\title{
Article
}

\section{ELLE of an Opportunity: Student Writers, Civic Audience, and Auction Genre}

Robin Sutherland

University of Prince Edward Island

William Chalmers

University of Prince Edward Island

Mark Currie

University of Prince Edward Island

\section{Introduction}

Every February, the Charlottetown chapter of the Canadian Heart \& Stroke (H\&S) Foundation hosts the "Razzle Dazzle Red" gala, a fundraising event that includes a sit-down dinner and silent and live auctions. "ELLE of an Opportunity" is the name of the very first live auction item, a coordinated jewelry set, listed in the gala program for 2014. Text developed for the jewelry enticed bidders to go big and to go fashionably home: student writer Dani MacDonald invited auction attendees to "hop right onto the trend of big, bold jewelry with this triad from ELLE Canada! The oversized ruby ring adds a note of edginess without compromising sophistication. Pair the ring with matching ELLE ruby earrings and necklace to complete your brave and bold new look!" Who could resist such a high-powered sales pitch?

For the past four years, the Writing Centre at the University of Prince Edward Island (UPEI) has partnered with the H\&S Foundation to produce the auction program for the Razzle Dazzle Red gala. The partnership was the result of a serendipitous alignment of people, opportunities, and an evolving writing centre mandate and has led to some unique and unexpected gains. Indeed, during the process of intellectualizing our role in this partnership, we have realized that our efforts are part of much larger mandates in higher education and writing centre practice.

First, our writing partnership acknowledges and advances the core vision of UPEI's Strategic Plan (2013): to "be a leader in delivering outstanding experiential learning opportunities that encourage our students to develop to their full potential in both the classroom and the 
Volume 27, 2017

http://journals.sfu.ca/cjsdw

community" (para. 5) ${ }^{1}$. In addition, because this partnership also involves broad writing development and mentorship of student tutors, we would argue that it adheres to a number of best practices listed in the "Statement on Writing Centres and Staffing" (Graves, 2016) recently endorsed by the Canadian Association for the Study of Discourse and Writing (CASDW), particularly that "Students who work with writing specialists at writing centres should improve their writing and critical thinking" (p. 5); "Writing Competency is a degree outcome for all university students" (p. 6); and "Peer Tutors need to be educated and mentored" (p. 7).

This paper presents three different perspectives of the writing partnership between UPEI and the H\&S Foundation. First, Robin Sutherland (writing centre coordinator) provides an overview of how the partnership evolved and the ways it has helped re-position the centre as a site of writing leadership by offering student tutors a chance to broaden their writing skills, develop a professional writing portfolio, and generally contribute to a positive writing culture on campus. Mark Currie (student tutor, writer, and writing centre project manager) then reflects upon the many conflicts and challenges experienced by student writers, as well as the tangible gains of the partnership. Finally, Bill Chalmers (science editor and undergraduate composition instructor) considers "auction text" as a legitimate, low-stakes writing genre that may have a place in undergraduate composition practice.

\section{"Sowing the Seeds" 2 : The Blossoming of a Community Writing Partnership (Robin Sutherland)}

UPEI's writing centre became involved with the H\&S Foundation when Bill Chalmers was offered the job of writing the gala program but wondered instead if our student tutors would be up to the task. At the next writing centre staff meeting, we discussed the idea, voted to undertake the work, and established the terms of our involvement: the writing would be done on a volunteer basis and require tutors to commit to at least two weekend writing or editing "sweatshops," and additional time, as needed. In lieu of the $\$ 500$ honorarium that was offered, we requested that writers receive public credit for their work: their initials would appear with the text they authored and a longer note of acknowledgement would be included in the gala program. I made it clear that tutors did not have to participate and that they would not be penalized (in their staff evaluations) for choosing not to participate. 3

During the first year of the partnership (winter 2014) and with no direct experience to draw upon (although Bill and I had both worked as professional writers and editors), we focused 
Volume 27, 2017

http://journals.sfu.ca/cjsdw

exclusively on the writing and the deadline. Tutor-writers attended two mandatory writing sweatshops, at which they wrote individually or brainstormed and developed auction texts together. A senior tutor was designated "Editrix-in-Chief" of the project and in addition to developing her own text for individual auction items, she also helped with the gruelling, intense, and never-ending revision process of our master text file. After we met our deadline and received hard copies of the gala program, Bill and I conducted a brief post-mortem of the experience. We concluded that if we were invited back the following year, we needed to rethink our strategy. Writing was the easy part. The true labour was-unsurprisingly-in the revision process and only one of our student writers had been involved in that experience.

With this in mind, we modified our approach when we were indeed invited for a repeat performance in the winter of 2015. Tutors were encouraged to start writing as soon as possible and were asked to bring a draft of their work to at least one mandatory editing sweatshop. As Bill and I worked with students during these revising sessions, we began to realize the serious pedagogical potential of "Project H\&S." In order to edit and revise effectively, for example, our student writers needed to give serious thought to their intended audience. If students are aware of producing research papers for an academic audience (their professors), research indicates that even such a scholarly covenant is often poorly understood (Badke, p. 72). To be able to stop and take the time to discuss this essential component of writing was a turning point for all of us. Who, exactly, were we writing for and what were the expectations of those readers? For perhaps the first time in their undergraduate careers, students were writing for someone other than a professor and as such, became conscious of the need to choose words, images, and narratives that would resonate with that new group. Auction text could be playful and at times even suggestive or edgy, but it had to be professional and respectful.

As we neared our submission deadline that year, we wondered what it would be like to attend the gala and see our writing at work. Project H\&S appeared to have given some momentum to my efforts in re-positioning UPEI's Writing Centre as a site of student writing leadership: at least one student tutor and Bill had both received MacLauchlan Prizes for Writing 4 for their creative auction copy and writing mentorship, respectively, for the 2014 fundraiser. Armed with such campus recognition, I successfully petitioned our VP Academic for a few tickets to the gala and off three of us went to Razzle Dazzle 2015. ${ }^{5}$ As the tutors and I filed past the silent auction tables, we joined our once-faceless "intended audience" in reading our work. Our text had been professionally formatted and prominently displayed with all the silent auction items and it was rather thrilling to see it in its final form. I speculated that our attendance at the gala might be 
Volume 27, 2017

http://journals.sfu.ca/cjsdw

the equivalent of presenting a paper at an academic conference or releasing a collection of poetry at a book launch. Even if academic writing and professional writing are two very different undertakings, with two very different intended outcomes, both offer students a chance to develop writing skills and be part of a larger writing community. In any event, the experience struck me as profound and I decided to ask for an entire table the following year.

In February 2016, with a few more MacLauchlan Prizes to our credit and additional support from Student Affairs and the Writing Centre, we bought enough tickets for all writers to attend the gala. ${ }^{6}$ Out came the ties and the suits, the high heels and the red lipstick, and it was a respectable group that congregated in the lobby of the Delta Hotel. This was the first time most of the students had ever attended such an event, at least without their parents, and with some pride and fascination, I watched my student staff mingle with Charlottetown's finest, wondering how a social scientist might interpret the scene. What did students think when they saw their writing on public display and as part of a larger, philanthropic whole? How were they engaging with the other people attending the gala? I concluded that the partnership with the Heart \& Stroke Foundation was as much about students developing as engaged citizens as it was about them developing as writers. I am pleased to report that in February 2017, we were once again successful in obtaining tickets for all writers to attend the gala. ${ }^{7}$

\section{"By Hook or By Crook"8: Creative Solutions for Coordinator Challenges (Robin Sutherland)}

UPEI is the only university on Prince Edward Island and is home to approximately 4,500 students. Most of these students are enrolled in undergraduate programs and are from the island. Students who work at UPEI's Writing Centre are typically undergraduates from the Faculty of Arts, majoring in English, History, or Psychology. On occasion, I have also hired students in the Bachelor of Education program and students from the Master of Arts in Island Studies (MAIS) program.

I became the writing centre coordinator at UPEI in the fall of 2012. I hold a Ph.D. in English Literature and a diploma in Technical and Professional Writing. My dissertation analyzed the writing of Lady Agnes Macdonald, the second wife of Sir John A. Macdonald, specifically her contributions to an emerging sense of Canada as told by the citizen-mother, a narrative type that draws upon post-colonial and feminist political theories. I refer to my doctoral research here because several issues that underpin post-colonial theory inform our discussions about our 
Volume 27, 2017

http://journals.sfu.ca/cjsdw

partnership with the Heart \& Stroke Foundation, such as concepts of privilege, and the economics and politics of community and space. Mark discusses the struggle some students had when thinking about privilege and I have contemplated my own role in leading students into what some might call a space of philanthropic consumerism. Was I professionally colonizing these young academic writers or contributing to their development as citizen-students who could move knowledgeably and effectively between campus and community? Naturally, I hoped the latter.

The Writing Centre at UPEI was a solid if rudimentary operation when I arrived. It was in its second of five years of external funding, which gave it (temporary) financial security and independence from the budget priorities that shaped other units. But the centre did not seem to have much of a presence on campus and lacked a formal training program for a staff made almost exclusively of full-time undergraduate students. My 28-hour a week, 10-month renewable contract imposed definite challenges on my time, but my hands-off, people-centred manager provided considerable latitude in terms of how I spent it. After much thought, I decided to spend my time on my tutors, reasoning that there were more of them than there was of me and that with the right training and mentorship they could extend a formidable reach across campus. But what would constitute such training and mentorship? I was in new and uncertain territory, so I retraced my steps and returned to the basics: we were here as a staff because we were writers and we loved working with words. Why not find opportunities to fuel this passion, while contributing to my staff's further writing development at the same time? Indeed, I wondered if by investing in our already-accomplished writing tutors, we might also help rebrand the centre as a site of student writing leadership, as opposed to a site of remedial student writing. Centers for Writing Excellence (CWEs) ${ }^{9}$ are not new (Issacs, 2011; Koch, 2011), but neither are negative associations of writing centres and skills deficits.

Project H\&S has proven to be an innovative sort of writing training for student tutors and has reinvigorated how my staff and I work together as a distinct community of writers. When we gather for an editing sweatshop, we gather as writing colleagues. We bring different degrees of creative flair and professional writing experience to the table, but we are there to write as a team. Our collaborative H\&S writing has therefore contributed to an increased sense of staff cohesion and enthusiasm, an energy that has come to characterize the atmosphere of our writing centre, and the dynamic of the appointments that we hold in that space.

Another benefit has been the knowledge that is gained from the writing exercise itself. If auction text is low-stakes writing, it is also highly challenging writing. Students are tasked to 
Volume 27, 2017

http://journals.sfu.ca/cjsdw

produce a two or three-sentence narrative for each auction item. Focus and brevity are essential and during our editing sweatshops students must weigh the value of every image, word, and punctuation mark in their texts. It is gruelling work, but for a group of wordsmiths, it is delicious and enthralling work. Tutors who participate in Project H\&S return to writing appointments with a reinvigorated sense of the craft of writing and the ability to write in a different genre; they also return with first-hand experience of writing in the elusive "real world," which they can then share with their peers.

Another quantifiable gain is a professional writing portfolio. Each year of the partnership we have generated between 100 and 120 individual pieces of auction text. To-date, 20 individual students have written for the fundraiser and 11 of them have graduated from UPEI with professional writing portfolios of up to 30 pieces of creative copy. If students originally participated in the project because it seemed like a fun thing to do or a volunteer experience they could list on their resumes, the experience has, among other things, introduced them to the legitimate job of creative copywriter.

Finally, the contributions that we make as a group of university writers resonate with various administrative imperatives, defined as "writing outreach" or "service learning," both of which can be developed "as a way to advance the mission of a liberal education" (Amare \& Grettano, 2007, p. 57), or as a type of "civic engagement," defined by David Smith as "involvement in the community, in the 'public sphere,' which includes politics and public policy, but also the social and commercial dimensions of human relationships" (as cited in Amare \& Grettano, 2007, p. 66). I do not wish to reduce our community writing partnership to an educational trend, nor do I wish to reduce the liberal arts to a justifiable job-training formula. However, I am sensitive to the need to be judicious in how I articulate our purpose and value. As the external funding for UPEI's Writing Centre comes to an end, I wonder if Project H\&S might serve as its own kind of auction text, promoting the work that we do to the people who can ensure we keep doing it.

\section{"Bootcamp was Never So Sweet"10: The Trials \& Triumphs of the Student Copywriter (Mark Currie)}

I have been involved in the first three years of Project H\&S, though my participation has evolved from writer to editor to mentor to project manager. In the first year of the partnership, I was also in my first year of graduate school and simply contributed creative copy along with the other tutor writers. None of us had engaged in copywriting before and so we approached the 
Volume 27, 2017

http://journals.sfu.ca/cjsdw

project with dramatic trial and error, combining what we had seen in "Mad Men" (decanters excluded) with youthful cynicism to give an edge to our words. During the inaugural year of the project, we had no precise formula to follow and every auction item was different and new to us. Therefore, we never felt like we were mastering an art form.

However, it was not simply our lack of experience that led to a wastebasket full of unusable drafts. I joined the project because the writing experience seemed like it could be a creative, challenging, and fun exercise, and it was. But it also brought about personal and professional challenges that I did not anticipate. As I worked on my auction texts and contemplated what exactly I was doing, I began to worry that my writing was contributing to an unsustainable and ineffective solution: throwing money at an issue. I felt that helping to entice bids for diamond earrings and sterling silver necklaces was, in fact, removing focus from the real issue at hand (heart disease) and adding to other problems stemming from materialism and overconsumption. Furthermore, my fellow writers and I realized that none of us had ever met anyone who had attended the fundraiser. Our attempts to imagine our audience acquired the flavour of jaded, preconceived notions of those who would be financially able to attend and participate: middle-aged and retired professionals. My colleagues and I were all full-time students working multiple part-time jobs, applying for scholarships and loans, and sometimes living with our parents or as many roommates as we could find to pay our way. A Grand Canyon-sized gap existed between writers and gala attendees, which made for an uneasy relationship.

Although we did not have the financial edge, we had our academic training, which meant we were able to think critically and to write analytically about a range of subjects like literature, history, psychology, and the sciences. Our professors wanted us to engage with relevant theories and be able to conduct in-depth research. Writing short, punny texts about luxurious auction things made many of us feel that our abilities were well above what was being asked of us. Were we selling ourselves out? I worried that the answer might be yes. Luckily, I continued with the project the following year and was given opportunity to reflect further on the subject.

During the second year of the project, I still felt the divide between the writer and the audience. Nothing had changed. No bridges had been built. The difference was my focus: the task was to write and edit quickly and collaboratively to meet a deadline, while still having some fun wordsmithing. I now see that my writing for the project began to improve when I removed the consideration of privilege and re-conceptualized the audience. When I wondered how someone might be able to enjoy an auction item, rather than whether the item would be enticing 
Volume 27, 2017

http://journals.sfu.ca/cjsdw

to someone of financial means, the line between the financial and the academic began to blur. I observed this first-hand when I attended the fundraising gala and saw the audience interact with my writing. I wanted to know if my writing "worked," regardless of the reader's socio-economic status. I watched and listened, questioning what I might have done differently when a reader gave no reaction, or feeling personally gratified when people obviously appreciated my writing by reading it aloud or chuckling at a well-turned phrase. Additionally, when I considered the intended function of my work as auction copy, I was professionally gratified to see that it had resonated with them when they placed a bid.

As we prepared for our third year of the writing partnership, I was appointed to the role of project manager. In addition to writing some of my own auction texts, I would also serve as liaison between the Writing Centre and the Heart \& Stroke Foundation, coordinate and assign packages of auction items to student writers, organize the editing sweatshops, and give our master text a final edit before submitting it. The administrative responsibilities proved easy. More challenging was the active role I took in mentoring younger writers during the editing sweatshops. I now had a better idea of how to tackle the work and we had developed a general formula for how to write text for auction items (identify a single metaphor or image, create a two- to three-sentence narrative, and use language appropriate for the narrative's theme), but I found myself struggling to support new writers who were unsettled by the experience and frustrated by the demands of the genre. The fast-paced writing environment, the many revisions that we proposed, and the numerous drafts that we asked for overwhelmed some writers. In a few cases, newer writers equated critique with a personal writing deficit or felt as if they had little room for real self-expression. In others, the collaborative nature of the project made some students feel like the writing they got credit for was not even their work. As writing tutors, we already appreciated how unnerving it was to entrust your writing to someone else. To entrust it to a colleague is particularly daunting, especially when you are writing in an unfamiliar genre. I did my best to bolster flagging egos and help younger writers work through the psychological barriers of the project. Yet, while many writers came with auction texts, accepted minor edits, and welcomed suggestions, there were times when authors struggled to create even first drafts and other instances when a text needed a major overhaul, adding tension to an otherwise fun endeavour.

Also quite challenging was the task of giving our master text file a final proofread for typos, errors, and appropriate length. If you have never written marketing text before, you might not appreciate just how difficult it is to develop a focused narrative for each auction item. Tutors 
Volume 27, 2017

http://journals.sfu.ca/cjsdw

who joined the auction-writing project came with their own styles of writing and their own voices, but personal writing styles or choices of language and tone did not always match the needs of the task. Many writers got caught up in the excitement and tried to incorporate three or four images or metaphors to highlight several features of a single auction item. The result was a great stew of allusions that unfortunately did not mesh together into one cohesive story. To the best of my diplomatic ability and while time allowed, I tried to make suggestions that would help writers streamline their ideas and do their own re-writes so they would still feel like the work was their own. Not everyone had the time to engage in this level of revision and sometimes I needed to take a heavy hand to the text to make it what the H\&S required. Since we were writing to a deadline, the more that writers resisted alterations to their writing, the greater was the need to make final changes without their input.

In the end, however, my role as project manager included much more than the production of auction texts and meeting a deadline. I wrote letters to our VP Academic to request funding to purchase a table at the gala (and a subsequent thank-you note and final report). I assisted with the editing and submission of a campus newsletter article that one of our student writers had written about the project. I was later asked to develop a workshop presentation to guide future student copywriters through the process of writing auction texts. I wrote, edited and managed a lot of words during the winter of 2016. At the time, I thought I was only doing my job. However, I now read all of these different tasks as chapters in the story of my own professional writing development. Project H\&S might be seen as an isolated episode about life in the copywriting trenches, yet it is part of a much more complex arrangement of interconnected writing stories (and genres). After our third year of Project H\&S, I saw the full significance of what I had accomplished as writer. Among other things, I now had an interesting "Professional Writing" section on my CV.

\section{"Bet You Didn't Account for This"11: Moving toward a Low-Stakes Genre of Auction Text (Bill Chalmers)}

Finding writing tasks that have meaning beyond the classroom is a constant challenge for teachers of undergraduate writing. Genres in the academy have been both problematic and problematized in and by first-year composition courses, given the somewhat insulated nature of undergraduate writing, especially when writers are just becoming aware of the conversations occurring around them in the various disciplines. Student writing is effectively isolated from 
Volume 27, 2017

http://journals.sfu.ca/cjsdw

audiences other than the professoriate and sometimes peers. For most students, the idea of writing for an "authentic" audience other than an academic one remains abstract, however much discussed and analysed in the composition classroom.

The opportunity to have students write for an audience within the community was too good to pass up. The low-stakes nature of the writing task held some appeal for the composition classroom, because such assignments are relatively quick to write and evaluate. In that sense, they provide an effective feedback loop for both students and instructors. However, since the H\&S writing task was fundamentally a professional commitment, as well as a bit of an experiment, Robin and I felt we needed to control a few variables. By choosing to enlist the writing centre tutors, we were confident that we had access to some of the most engaged student writers on campus; our decision also meant that we would avoid any potential scheduling conflicts between the winter semester and the timeline of the writing task.

In the context of an off-campus community, the auction texts would certainly retain the brevity of low-stakes writing, but would acquire the weight of authenticity of the rhetorical situation, to which we did not give much thought before we engaged in it. The project simply promised to be interesting and dynamic, with a firm deadline, and Robin and I liked the challenge of writing in a new genre with the students; we would figure it out as we went. There was precious little formal guidance on the Internet for writing auction texts-as unbelievable as that may sound-beyond stating the rather obvious, such as "keep it simple" (Miller, 2017), "include historical significance, rarity and any pertinent facts that could increase bidding" (Charity Fundraising, 2010), and use "catchy and clever" titles and "brief and creative paragraph[s]" (Lauth, 2015). Good advice, to be sure, but still rather broad and a long way from constituting a meaningful set of conventions or genre features. Armed with photos of the auction items, a copy of the previous year's descriptions, and an occasion and purpose for writing but little else, we organized the students and began to write. Only once we began writing did the elements of the rhetorical situation (purpose, audience, and occasion) begin to reveal themselves more clearly.

The opportunity to reach a community audience with student writing was not lost on us, either; student writing would play an important role in a high-profile community event. Carolyn Miller (1984) has famously argued that "a rhetorically sound definition of genre must be centered not on the substance or the form of discourse but on the action it is used to accomplish" (p. 151), a stance with which our auction text writing neatly aligned. We can say with certainty that these texts constituted a "social action," as they supported a major non-profit 
Volume 27, 2017

http://journals.sfu.ca/cjsdw

organization's annual, community-based fundraising event. Miller (1984) has also drawn on some of Kenneth Burke's language to extend the notion of genre as a social action that is, "pragmatic, fully rhetorical, [and] a point of connection between intention and effect" (p. 153). Arguably, our auction texts were nothing if not pragmatic. The extent of their pragmatism depended entirely upon their rhetorical effectiveness, which in this case could be quantified, at least in part and perhaps somewhat crassly, in dollars raised for the Heart \& Stroke Foundation.

In Burkean terms, the auction texts are lovely examples of gestures towards consubstantiation: each of the texts attempted to overcome the division between its (young student) writer and (mature professional) audience, such that the reader would identify with the text and its referent in a way sufficiently compelling to elicit a bid. Identification with the audience was the first task of the writers, though they often struggled to imagine this demographic group and identify with it. As Mark noted above, student writers quickly became acutely aware of the social, economic, political, and chronological distances between themselves and their audience and were forced to re-evaluate or temporarily set aside personal beliefs, biases, and assumptions for the cause. Consubstantiation, if indeed possible to achieve, required a calculated empathy, propelled by a profit motive. In the end, it was much as Burke (1969) described: "You persuade a man only insofar as you can talk his language" (p.55), and the students learned to talk the language of their audience.

Our definition of the auction text genre developed through negation, in a sense. We knew what would not work as soon as we saw it, but we were well into the second year of the partnership before we became able to articulate a set of genre features. All the while, of course, student writers were muddling along beside us and writing well in the absence of any really concrete rules or formula for the genre. Swales (1990) tells us that "recognition of purposes provides the rationale, while the rationale gives rise to constraining conventions" (p. 53), but the purpose and rationale of these texts were never in question for us. Of their "family resemblance", however, we were less certain. We knew auction texts had to be short. We knew they needed a hook, and we knew they had to hold the reader's attention for two or three sentences only, in the context of a hundred or so other short texts trying to do the same. Titles became significant as obvious hooks. Thematic and narrative consistency revealed themselves as essential after some early drafts offered cultural and musical mashups. These were mini-stories, we realized. They were sudden fictions, rife with the demands that poetry and short stories place on economy, word choice, and clarity. 
Volume 27, 2017

http://journals.sfu.ca/cjsdw

Swales (1990) states that "a genre is a class of communicative events" and that "a communicative event is one in which language [...] plays both a significant and indispensable role" (p. 45). In a silent auction, the descriptive/persuasive text may not be indispensable, but it certainly played a significant role in readers' responses to the items up for auction. In each of the four years we have written for the Heart \& Stroke fundraiser, we have been told that our auction texts have been responsible for one of the conversational threads that characterizes the evening's event. We might say, modestly, that our texts have gained a reputation at the event and are now anticipated and enjoyed for their rhetorical value as much as for their social and civic functions.

A discourse community's nomenclature for genres is an important source of insight, says Swales (1990). After four years of producing these texts we can comfortably, if retrospectively, identify their family features as follows:

1. Use of a single metaphor or image suggested by the auction item;

2. Development of a two or three sentence narrative;

3. Use of language appropriate to the narrative (e.g. an irreverent metaphor or image is likely to succeed using alliteration or puns, while a romantic metaphor or image is likely more effective if it makes use of lush, descriptive words);

4. Use of sentence fragments or punctuation strategically-for emphasis-and the use of gapping and compression.

We have also observed some recurring sub-genres (family branches?) we might group and name pop culture (movies, music, \& TV), word play (alliteration \& puns), literary, geographical (local references), and themed (love \& Valentine's Day) sub-genres. The final two in this list are specific to this event's timing and location, but are likely generalizable to other events and locales.

Identification and classification of sub-genres seems to be an important analytical step in a discussion that seeks to illuminate features. Even though this was not intended as an explicit part of the writing process, the need to, for instance, decide whether or not to use a Disney reference rather than a Shakespeare reference gave frequent rise to serious considerations and discussions about audience, objects, culture, and rhetorical effect.

Miller (1984) has opened up the range of discourses and texts that might be legitimately discussed as genres beyond those of most interest to rhetorical scholars to include more 
Volume 27, 2017

http://journals.sfu.ca/cjsdw

"homely" discourses, such as letters, user manuals, eulogies, and so on, in order to "take seriously the rhetoric in which we are immersed and situations in which we find ourselves" (p. 155). In opening up the genre canon, Miller's emphasis on the social situation might seem to draw attention away from the texts themselves, but in many ways the rhetoric is responsible for the tone and tenor of the social setting in which it is present.

Why should we bother to identify or characterize the features and familial resemblances of these texts? We should do so in order not to be able to teach the genre, but in order to provide some form of guidance and structure to students writing within this genre for the first time. Each year we have tried to improve the process based on the previous year's experiences and we now have a dynamic and evolving tool with which we can effectively scaffold student writing of auction texts. You might still ask: "So what?" To which we might reply: If a central tenet of the university's mandate is to shape productive, aware, thinking citizens, then the small genre of the auction text punches well above its weight class and provides student writers with a writing opportunity layered with lessons in cultural literacy, audience awareness, professional writing and copy-editing, and social responsibility.

\section{"Down the Bidding Hole"12: A Few Concluding Remarks}

What is the relevance of this single writing initiative at UPEI, particularly to writing centre staff and undergraduate composition instructors elsewhere? We work in vastly different environments and with varying degrees of security. However, most of us are increasingly challenged to do more with less and all of us will likely find ourselves the subject of a prioritization exercise or a financial rationalization at some point. It is true that the best-crafted defences of writing centre work or writing instruction do not necessarily ensure the institutional survival of our centres or our colleagues; regardless of the merits of Project H\&S that we have discussed in this article, there is no guarantee that the initiative will secure future funding for UPEI's Writing Centre. We appear to be playing a daunting game, yet we work in an academic environment where creative solutions should matter to those entrusted with the stewardship of higher education. In addition, we do not sit at the table alone. Our students bring with them enthusiasm, talent, and a critical mass and voice, and our writing brings with it passion and power. Not bad odds, perhaps, in a profession that seems like a bit of a gamble at times. 
Volume 27, 2017

http://journals.sfu.ca/cjsdw

\section{Endnotes}

1. UPEI's Strategic Plan also appeals to the entire university community, in that "Through shared responsibility of faculty, staff, and students we are called to a duty of creating an enriched learning environment that fosters student success through engagement and experience" (A.3). Such inclusion can be particularly important to those Writing Centre Coordinators who work with students, but outside of the classroom. There are many spaces on and off campus that offer "an enriched learning environment."

2. Connor Kelly wrote "Sow the Seeds" for the 2015 fundraiser. Auction text read: "Even Eden started out as a patch of dirt and someone's idea. Enjoy home grown apples with no worries. Use this gift card to grow your own slice of Paradise."

3. In 2014, nine tutors wrote for the project (out of a staff of 15); in 2015, seven tutors wrote for the project (out of a staff of 13); in 2016, eleven tutors wrote for the project (out of a staff of 16); and in 2017, seven tutors wrote for the project (out of a staff of 15).

4. MacLauchlan Prizes for Writing are awarded to students who have demonstrated a proficiency in writing, or a commitment to becoming a better writer and to staff and faculty involved in the promotion of good writing through different partnerships or initiatives. Most of the awards are granted based on writing submitted for UPEI courses but a separate category involves writing that is shared with an external readership.

5. I bought my own ticket to the 2015 gala and attended with senior tutors Mark Currie and Elliot Ince, whose tickets were purchased by the VP Academic.

6. In 2016, nine out of eleven writers attended the gala. Bill Chalmers and one of the student tutors were unable to attend.

7. Tickets for the 2017 gala were purchased with support from the Vice President Academic and Research and the Writing Centre. All requests for funding were written by senior tutor and project manager Jess Reynolds.

8. Keri McCaffrey wrote "By Hook or By Crook" for the 2015 fundraiser. Auction text read: "Enjoy fresh, delicious seafood on the wharf this summer when you reel in this catch-of-the-day. Four meals at Richard's on the Wharf? Sounds like a new family tradition. Cast your hook and sea!"

9. I have found the essays by Emily Isaacs and Robert T. Koch in Before and After the Tutorial: Writing Centers and Institutional Relationships helpful in introducing the concept and goals of Centers for Writing Excellence (CWEs), particularly their discussions about terminology and the 
Volume 27, 2017

http://journals.sfu.ca/cjsdw

appeal of accomplishment rather than deficit writing centre models to university administrators and advancement.

10. Ruby Madigan and Bill Chalmers wrote "Bootcamp was Never So Sweet" for the 2014 fundraiser. Auction text read: "Have you got what it takes to survive a day of hardcore kitchen training? We're not talking KP duty here, folks: this is you and a knife going mano-a-mano with vegetables and meat. This is you learning the subtle art of stealth seasoning. Find out what you (and the dishes) are made of."

11. Chris Thompson wrote "Bet You Didn't Account for This" for the 2015 fundraiser. Auction text read: "Spend big tonight! (But remember to keep your receipts.) Use the services of your MRSB accountant to write off your purchases from this auction on your next tax return.”

12. Grace Gibson and Mark Currie wrote "Down the Bidding Hole" for the 2016 fundraiser. Auction text read: "Tea parties are not just for the Cheshire Cat and the Mad Hatter. Your fancy new pottery collection is so stylish that everyone will want to be there, including the White Rabbit. Don't be late, don't be late for a very important... bid.!"

\section{References}

Amare, N., \& Grettano, T. (2007). "Writing outreach as community engagement.” WPA: Writing program administration, $30(3), 57-74$.

Badke, W. (2014). Those baffling assignments. Online Searcher, 38, 71-73.

Burke, K. (1969). A rhetoric of motives. Oakland, CA: University of California Press.

Graves, R. (2016). Statement on writing centres and staffing. Canadian Journal for Studies in Discourse and Writing, 26, 5-10.

Charity Fundraising. (2010). Writing descriptions for your silent auction items. Retrieved from https://blog.cfr1.org/writing-descriptions-silent-auction-items/

Isaacs, E. (2011). The emergence of centers of writing excellence. In N. Mauriello, W. J. Macauley Jr, \& R. T. Koch (Eds.), Before and after the tutorial: Writing centers and institutional relationships (pp. 131-149). New York, NY: Hampton Press.

Koch, R. T. (2011). Centers for writing excellence and the construction of civic relationships. In N. Mauriello, W. J. Macauley Jr, \& R. T. Koch (Eds.), Before and after the tutorial: Writing centers and institutional relationships (pp. 131-149). New York, NY: Hampton Press.

Lauth, I. (n.d.). Bid sheets 101: Improve your silent auction with better bid sheets [Blog post]. Retrieved from http://blog.winspireme.com 
Volume 27, 2017

http://journals.sfu.ca/cjsdw

Miller, C. (1984). Genre as social action, Quarterly Journal of Speech. 70, 151-167.

Miller, J. (2017). Keep item descriptions simple. Retrieved from http://www.charityauctioneer.com

Swales, J. (1990). Genre analysis: English in academic and research settings. New York, NY: Cambridge University Press.

University of Prince Edward Island. (2013). UPEI Strategic Plan. Retrieved from http://www.upei.ca/about-upei/upei-strategic-plan 